\title{
BMJ Open Neurokinin-1 antagonist orvepitant for EGFRI-induced pruritus in patients with cancer: a randomised, placebo- controlled phase II trial
}

\author{
Bruno Vincenzi (D) , ${ }^{1}$ Mike Trower (D) , ${ }^{2}$ Ajay Duggal (D) , ${ }^{3}$ Pamela Guglielmini (D) ,4 \\ Peter Harris (D) , ${ }^{2}$ David Jackson (D) , ${ }^{5}$ Mario E Lacouture (D) , 6 \\ Emiliangelo Ratti (D) , ${ }^{2}$ Giuseppe Tonini (D) , ${ }^{1}$ Andrew Wood (D) ,7 Sonja Ständer (D) ${ }^{8}$
}

To cite: Vincenzi B, Trower M, Duggal A, et al. Neurokinin-1 antagonist orvepitant for EGFRI-induced pruritus in patients with cancer: a randomised, placebo-controlled phase II trial. BMJ Open 2020;10:e030114. doi:10.1136/ bmjopen-2019-030114

- Prepublication history for this paper is available online. To view these files, please visit the journal online (http://dx.doi. org/10.1136/bmjopen-2019030114).

BV and MT contributed equally.

Received 01 March 2019 Revised 11 December 2019 Accepted 13 January 2020

\section{Check for updates}

(C) Author(s) (or their employer(s)) 2020. Re-use permitted under CC BY-NC. No commercial re-use. See rights and permissions. Published by BMJ.

For numbered affiliations see end of article.

\section{Correspondence to} Dr Mike Trower;

mike.trower@nerretherapeutics. com

\section{ABSTRACT}

Objective To evaluate the efficacy of orvepitant (10 or $30 \mathrm{mg}$ given once daily, orally for 4 weeks), a neurokinin- 1 receptor antagonist, compared with placebo in reducing the intensity of epidermal growth factor receptor inhibitor (EGFRI)-induced intense pruritus.

Design Randomised, double-blind, placebo-controlled clinical trial.

Setting 15 hospitals in Italy and five hospitals in the UK. Participants 44 patients aged $\geq 18$ years receiving an EGFRI for a histologically confirmed malignant solid tumour and experiencing moderate or intense pruritus after EGFRI treatment.

Intervention 30 or $10 \mathrm{mg}$ orvepitant or placebo tablets once daily for 4 weeks (randomised 1:1:1).

Primary and secondary outcome measures The primary endpoint was change from baseline in mean patient-recorded numerical rating scale (NRS) score (over the last three recordings) at week 4 . Secondary outcome measures were NRS score, verbal rating scale score, Skindex-16 and Leeds Sleep Evaluation Questionnaire at each study visit (baseline, weeks 1, $4,8)$; rescue medication use; EGFRI dose reduction; and study withdrawal because of intense uncontrolled pruritus.

Results The trial was terminated early because of recruitment challenges; only 44 of the planned 90 patients were randomised. All patients were analysed for efficacy and safety. Mean NRS score change from baseline to week 4 was -2.78 (SD: 2.64) points in the $30 \mathrm{mg}$ group, -3.04 (SD: 3.06 ) points in the $10 \mathrm{mg}$ group and -3.21 (SD: 1.77) points in the placebo group; the difference between orvepitant and placebo was not statistically significant. No safety signal was detected. Adverse events related to orvepitant (asthenia, dizziness, dry mouth, hyperhidrosis) were all of mild or moderate severity.

Conclusions Orvepitant was safe and well tolerated. No difference in NRS score between the orvepitant and placebo groups was observed at the week 4 primary endpoint. A number of explanations for this outcome are possible.

Trial registration number EudraCT2013-002763-25.

\section{Strengths and limitations of this study}

- The RELIEVE 1 study was the first randomised, double-blind, placebo-controlled study of a neurokinin-1 antagonist for epidermal growth factor receptor inhibitor-induced pruritus.

- Patients reported scores for the primary endpoint of reduction of itch intensity on a daily basis using an interactive voice response system.

- Effects on sleep and quality of life were also measured

- Itch is a subjective symptom and thus susceptible to a placebo effect.

- The enrolment target was not reached because of recruitment problems in the target population.

\section{INTRODUCTION}

While targeted biological therapies have increased patient survival for several tumour types, they are linked with a variety of adverse events (AE), particularly dermatological AEs, including acneiform rash, hair changes, mucositis, xerosis/fissures, paronychia and pruritus. Epidermal growth factor receptor inhibitors (EGFRI) specifically are associated with these dermatological AEs that can require dose modification or treatment interruptions and thus interfere with these potentially life-prolonging therapies. ${ }^{1-5}$ Rash, xerosis and pruritus have the greatest impact on patient quality of life. ${ }^{5-7}$ Pruritus incidence reported in clinical trials of anti-EGFR monoclonal antibodies $(\mathrm{mAb})$ and smallmolecule EGFRIs ranges from $8 \%$ to $69 \%$ depending on the agent involved. ${ }^{8}$ EGFRIinduced pruritus may be under-reported or incompletely reported in clinical studies. ${ }^{10}$ In a survey of patients with cancer and survivors, pruritus is common and debilitating. ${ }^{11} 12$ Lacouture et al reported that pruritus occurs in approximately half of all patients treated 
with EGFRIs. ${ }^{4}$ Finally, in a review of interviews conducted with 100 patients taking mainly EGFR mAbs, $72 \%$ of patients reported experiencing pruritus. ${ }^{13} \mathrm{~A}$ safe and effective cancer-supportive care therapy to ameliorate the itching burden these patients experience is urgently needed.

Neurokinin-1 (NK1) receptors are 7-transmembrane receptors with a preferred peptide agonist ligand of substance $\mathrm{P}(\mathrm{SP}) .{ }^{14} \mathrm{SP}$ produced by peripheral skin sensory nerve fibres is thought to promote itching via activation of NK1 receptors on keratinocytes and mast cells causing local inflammatory and vasodilatory effects. ${ }^{15}$ Interestingly, Gerber et al reported that mast cells significantly accumulate in the lesional skin of patients treated with EGFRIs and suggested that the antipruritic activity of the NK1 receptor antagonist aprepitant in this population is achieved by blocking the activation of mast cell NK1 receptors by SP, thereby preventing the release of mast cell histamine and other proinflammatory/pruritogenic mediators. ${ }^{16-18}$ Recently, another receptor, the Mas-related G-protein coupled receptor member X2, has been shown to be activated in humans by $\mathrm{SP}$, and this interaction may contribute additionally to the proinflammatory effects mediated by mast cell degranulation. ${ }^{19} \mathrm{SP}$ and the NK1 receptor are also widely expressed centrally and have a role in transmission of the peripheral itch signal via the spinal superficial dorsal horn to higher brain centres for processing. ${ }^{20}$ In rodents scratching behaviour can be blocked by neurotoxic destruction of spinal NK1 receptor-expressing neurons, ${ }^{21}{ }^{22}$ and Tac1 (the gene encoding SP)-expressing spinal neurons have also been linked to the promotion of scratching behaviour. ${ }^{23}$ Intradermal injection of SP in humans causes pruritus, erythema and oedema. ${ }^{24-26}$ Scratching behaviour induced by intradermal injection of either SP or an NK1 agonist or topical administration of a hapten in animals can all be profoundly reduced by NK1 antagonist treatment, including both orvepitant and aprepitant. ${ }^{27-30}$ These data suggest that the NK1 receptor system is involved in itch signalling and therefore blockade of these pathways with NK1 receptor antagonists represents a potentially promising therapy for pruritic conditions, including EGFRI-induced pruritus. ${ }^{32}$

Aprepitant (Emend, formerly MK-869) is the first commercially available drug of a new class of NK1 receptor antagonists for the prevention of chemotherapyinduced and postoperative nausea and vomiting. It has been evaluated in numerous open-label clinical studies of patients suffering from treatment-refractory pruritus, including a large number of patients suffering with acute EGFRI-induced pruritus. ${ }^{33-49}$ In these uncontrolled studies, aprepitant acted as a rapid and highly effective antipruritic medication that also significantly improved patients' quality of life, leading to advocacy for clinical assessment of aprepitant and other emerging NK1 receptor antagonists in patients receiving agents with a high risk of pruritus. ${ }^{50}$

Like aprepitant, orvepitant is an orally active, potent, brain-penetrant and selective non-surmountable
NK1 antagonist that blocks SP signalling. ${ }^{51-53}$ These compounds are active in the well-characterised NK1 receptor pharmacodynamic gerbil foot-tapping model, in preclinical models of anxiety, ${ }^{51-54}$ and, as reported above, in the gerbil scratching behaviour model. ${ }^{28}{ }^{29} \mathrm{In}$ humans both compounds have pharmacokinetic properties consistent with once-daily oral dosing sufficient to achieve therapeutic plasma exposures that have high levels of central NK1 receptor occupancy. ${ }^{556}$ Thus, orvepitant would be expected to achieve antipruritic efficacy similar to that of aprepitant in patients suffering from intense itch as a result of EGFRI treatment. The RELIEVE 1 study evaluating the efficacy and safety of orvepitant is the first randomised, double-blind, placebo-controlled study of an NK1 antagonist for EGFRI-induced pruritus.

\section{METHODS}

\section{Patient and public involvement}

The indication, research questions and study endpoint outcome measures were selected based on the authors' expert understanding in the care of affected patients, their needs and therapy preferences, without direct communication of the study design to patients. Experience from guideline work, which involved patients' preferences, was also carried over into the study design. Patients were not involved in the recruitment nor conduct of the study, nor the interpretation of results. No commitment was made to disseminate the results to study participants. Patients assessed the burden of the intervention themselves. Patients were not invited to contribute to the writing nor editing of this document for either readability or accuracy.

\section{Study design and enrolment}

The primary objective of this exploratory phase II, multicentre, randomised, double-blind, placebo-controlled clinical trial was to evaluate the efficacy of orvepitant compared with placebo in reducing the intensity of intense EGFRI-induced pruritus. Pruritus intensity was measured primarily by change from baseline in patientrecorded numerical rating scale (NRS) score ranging from 0 (no itch) to 10 (worst itch imaginable) points. On the basis of an assumed between-patient SD of 2 points, ${ }^{8} 23$ patients per treatment arm were required to provide $80 \%$ power for a two-sided $5 \%$ significance level hypothesis test to achieve a significant result when the true difference is at least 2 points. It was thus planned to enrol 30 patients per arm (90 total). After 20 months of recruitment, this target was far from being reached, and a blinded analysis of data variance showing between-patient SD of 2.6 points indicated that it was highly unlikely that a statistically robust assessment of benefit could be made even if enrolment were completed. The sponsor decided to terminate the enrolment. However, the study data for all enrolled patients were analysed.

\section{Patients and treatments}

Patients were enrolled at 15 hospitals in Italy and five hospitals in the UK between 13 November 2013 and 11 
May 2015. Key eligibility criteria were age 18 years and older, monotherapy with an EGFRI (including cetuximab, panitumumab, erlotinib, gefitinib, lapatinib and afatinib) for a histologically confirmed malignant solid tumour, moderate or intense pruritus after treatment with the EGFRI (defined as the mean of between 2 and 7 daily patient-reported average pruritus intensity NRS scores initially $\geq 7$ and subsequently changed in April 2014 to $\geq 5$ to improve study recruitment), pruritus treatment within the previous 3 months and no use of aprepitant or fosaprepitant in the previous 4 weeks. The investigators randomised eligible patients according to a central randomisation code generated by the sponsor using an interactive voice response system (IVRS). The patients were assigned in a 1:1:1 ratio to receive $30 \mathrm{mg}$ orvepitant, $10 \mathrm{mg}$ orvepitant or placebo tablets once daily (in the evening before bedtime) for 4 weeks. Randomisation was stratified by investigational site; block size was 6 . Placebo tablets were identical in appearance to orvepitant tablets.

\section{Assessments}

Patients were followed up for 4 weeks after treatment was completed or discontinued. Patients reported their NRS scores daily using an IVRS between baseline and week 8. At each study visit (baseline, week 1 , week 4 , week 8) an NRS score and a verbal rating scale (VRS) score were recorded. The VRS score was assigned in response to the following questions: How intense was your pruritus during the past 24 hours? Did you have no pruritus, weak pruritus, moderate pruritus, severe pruritus or very severe pruritus? Scores ranged from 0 (no pruritus) to 4 (very severe pruritus). Both the NRS and the VRS are validated instruments for the measurement of pruritus intensity. ${ }^{57}$ At each study visit, the patients also completed the Skindex-16 (an instrument to measure the effects of skin disease on health-related quality of life), ${ }^{58}$ and the Leeds Sleep Evaluation Questionnaire (LSEQ; a 10-item instrument to assess changes in sleep quality over the course of an intervention). Safety was assessed by physical examination (including Eastern Cooperative Oncology Group (ECOG) status) and 12-lead ECG at baseline and week 8 , vital signs and laboratory tests (haematology, serum biochemistry, urinalysis) at each visit and recording of AEs throughout the study. AEs were graded and categorised according to the National Cancer Institute's Common Terminology Criteria for Adverse Events. Use of concomitant medications, including EGFRIs and any rescue medication, was recorded throughout the study. Sparse pharmacokinetic sampling was conducted to allow for exploratory analysis of the correlation of orvepitant plasma levels with clinical efficacy and secondary assessment scores.

\section{Endpoints}

The primary endpoint was change from baseline in mean patient-recorded NRS score (over the last three recordings) at week 4. Secondary endpoints were also evaluated: change from baseline in mean patient-recorded NRS score (last three recordings) each week; change from baseline in mean patient-recorded NRS score (all values in the week) at weeks 1, 4, 8; change from baseline in patient-recorded NRS score at days 2, 3, 4, 5, 6, 7, 8; change from week 4 in patient-recorded NRS score (over the last three recordings) at weeks 5, 6, 7, 8; change from week 4 in VRS score at week 8; change from baseline in Skindex-16 quality of life at weeks 1, 4, 8; change from baseline in LSEQ at weeks 1, 4, 8; rescue medication use; EGFRI dose reduction; and study withdrawal because of intense uncontrolled pruritus.

\section{Statistical analysis}

Efficacy endpoints were analysed in the modified intentionto-treat (mITT) population of all randomised patients who had received at least the first dose of study medication and had at least one post-treatment efficacy assessment. The primary endpoint was analysed by mixed-model repeated measures analysis with the primary inference being the change from baseline in patient-reported NRS scores averaged across the last 3 values of the fourth week of dosing fitted as the response variable in the mixed model. The model included treatment group, study pooled site, study visit, the interaction between study visit and treatment group, the covariate (the baseline value of the variable being analysed) and the interaction between baseline covariate and visit. The three treatment groups were analysed together in one model. Point estimates and corresponding 95\% CIs were constructed for the difference between each dose of orvepitant and placebo for each week. The primary efficacy endpoint was tested at a 5\% level of significance using a two-sided test to test orvepitant $30 \mathrm{mg}$ versus placebo, and no adjustment for multiple comparisons was made for the patient-recorded NRS score orvepitant $10 \mathrm{mg}$ versus placebo test or the secondary and exploratory endpoints. Safety was analysed in the safety population of all patients who received a dose of study medication using descriptive statistics.

\section{RESULTS \\ Patients}

A total of 44 patients were randomised and treated: 16 to orvepitant $30 \mathrm{mg}, 14$ to orvepitant $10 \mathrm{mg}$ and 14 to placebo. Nine patients discontinued the study (figure 1). All patients were Caucasian, and $26(59 \%)$ were male and $18(41 \%)$ female. Median age was 68 years (range: $35-83$ years), and $32(73 \%)$ patients were aged 65 or older. Mean baseline NRS score ranged from 5.88 (SD: 0.93) in the placebo group to 6.68 (SD: 1.28) in the $30 \mathrm{mg}$ orvepitant group. At baseline, most patients had moderate to severe pruritus, and the most common locations were the head (specifically the scalp, $26(59 \%)$ patients) and the trunk (11 (25\%)). Baseline assessments of acneiform rash and maculopapular rash showed a similar pattern (table 1).

The median dose number was 28 (range: 1-35) in the $30 \mathrm{mg}$ group, 28 (range: $1-35$ ) in the $10 \mathrm{mg}$ group and 29 (range: 28-39) in the placebo group. Five (11\%) patients (all in the orvepitant groups) took the study drug for 1 week 


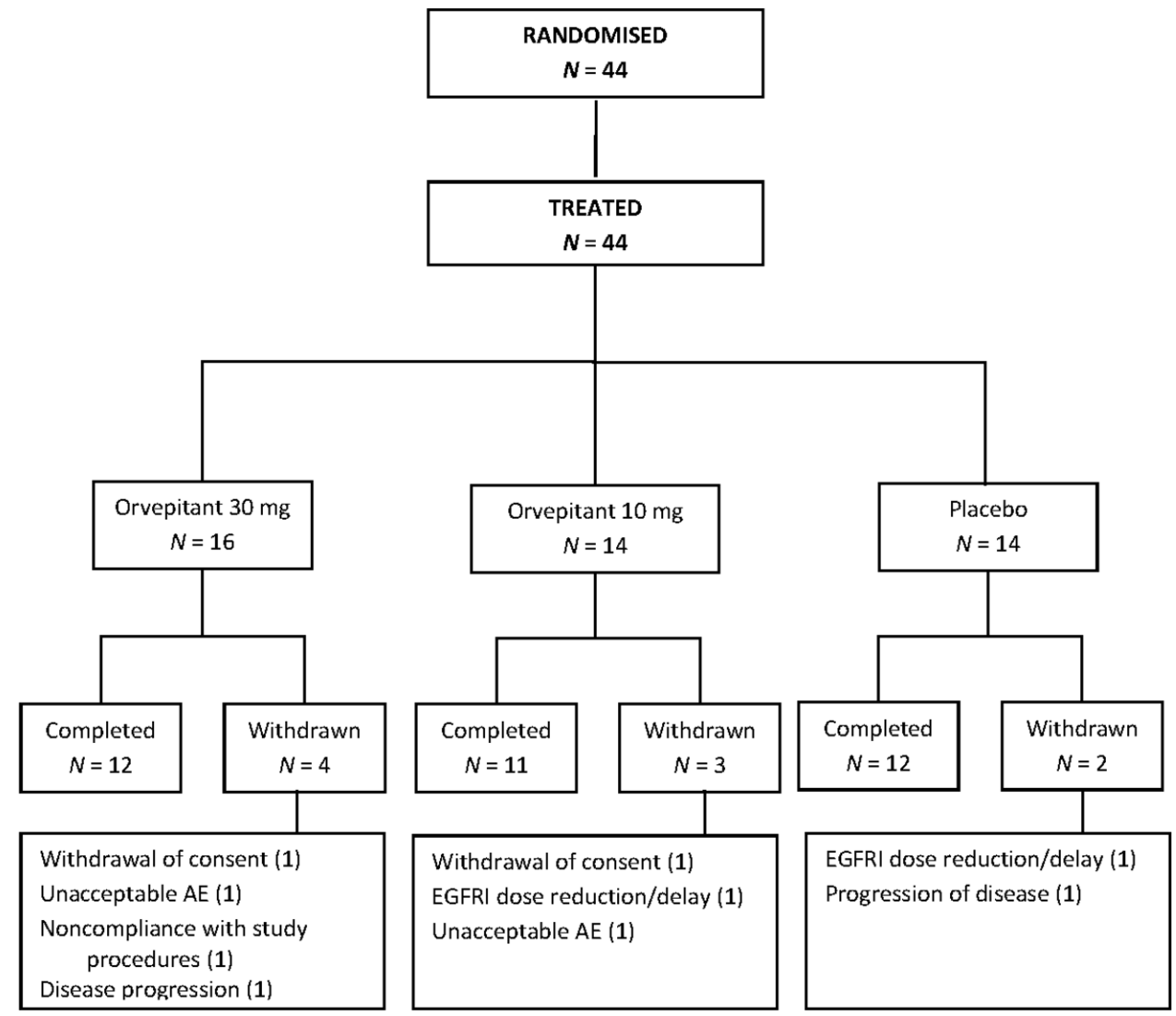

Figure 1 Disposition of RELIEVE 1 patients. AE, adverse event; EGFRI, epidermal growth factor receptor inhibitor.

or less; $18(41 \%)$ patients took the study drug (orvepitant or placebo) for 1-4 weeks; and $21(48 \%)$ took the study drug for $>4$ weeks (maximum: 39 days).

All 44 patients were included in the mITT and safety populations and analysed according to the randomised treatment.

\section{Efficacy}

Patient compliance with daily reporting of NRS score was high; mean compliance rate was $92 \%$, and median compliance rate was $100 \%$. At week 4, 38 patients remained in the study. NRS score decreased from baseline to week 4 in all three groups (table 2). The difference between orvepitant and placebo was not, however, statistically significant (30 mg group: $\mathrm{p}=0.12,10 \mathrm{mg}$ group: $\mathrm{p}=0.19$ ).

Secondary NRS and VRS endpoints reflected the results for the primary endpoint (table 3). Change from baseline in Skindex-16 and LSEQ score showed no difference between the treatment groups at any time point. Rescue medication use and EGFRI dose reduction both occurred in $7(16 \%)$ patients (three in the orvepitant $30 \mathrm{mg}$ group and two each in the orvepitant $10 \mathrm{mg}$ and placebo groups). No patients withdrew from the study because of intense uncontrolled pruritus.

Analyses of pharmacokinetic data were not conducted because of the lack of efficacy observed.

\section{Safety}

No safety signal was detected. A total of $34(77 \%)$ patients experienced a treatment-emergent $\mathrm{AE}$, but no unexpected
AEs were reported. Only four mild and moderate AEs were considered by investigators to be related to orvepitant (table 4). AEs that occurred in $>5 \%$ of patients were asthenia (8 (18\%) patients), skin toxicity (7 (16\%) patients; term reported by the investigators was skin toxicity, which for EGFRIs commonly includes reactions such as skin rash, skin dryness (xerosis), pruritus, paronychia, hair abnormality, mucositis, and increased growth of the eyelashes or facial hair $\left.{ }^{59}\right)$ diarrhoea (4 (9\%) patients), cough (3 (7\%) patients), rash (3 $(7 \%)$ patients; terms as reported by the investigators included worsening of rash; hands, ankle and face rash; and rash cutaneous) and anaemia (3 (7\%) patients). These more common AEs occurred in similar rates in the active and placebo groups except for anaemia and rash, which occurred infrequently and only in patients who received orvepitant. There was no apparent relationship between incidence or severity of AEs and orvepitant dose. No serious AEs were reported.

No clinically significant changes in laboratory results, vital signs, physical examination findings, ECOG status or ECG parameters were related to orvepitant.

\section{DISCUSSION}

\section{Interpretation of the results}

Orvepitant appeared safe and well tolerated, and the findings in this study are consistent with the substantial safety database accumulated to date on this product in different populations. The safety profile exhibited allows further investigation of orvepitant in this or other indications, 
Table 1 Demographic and baseline characteristics

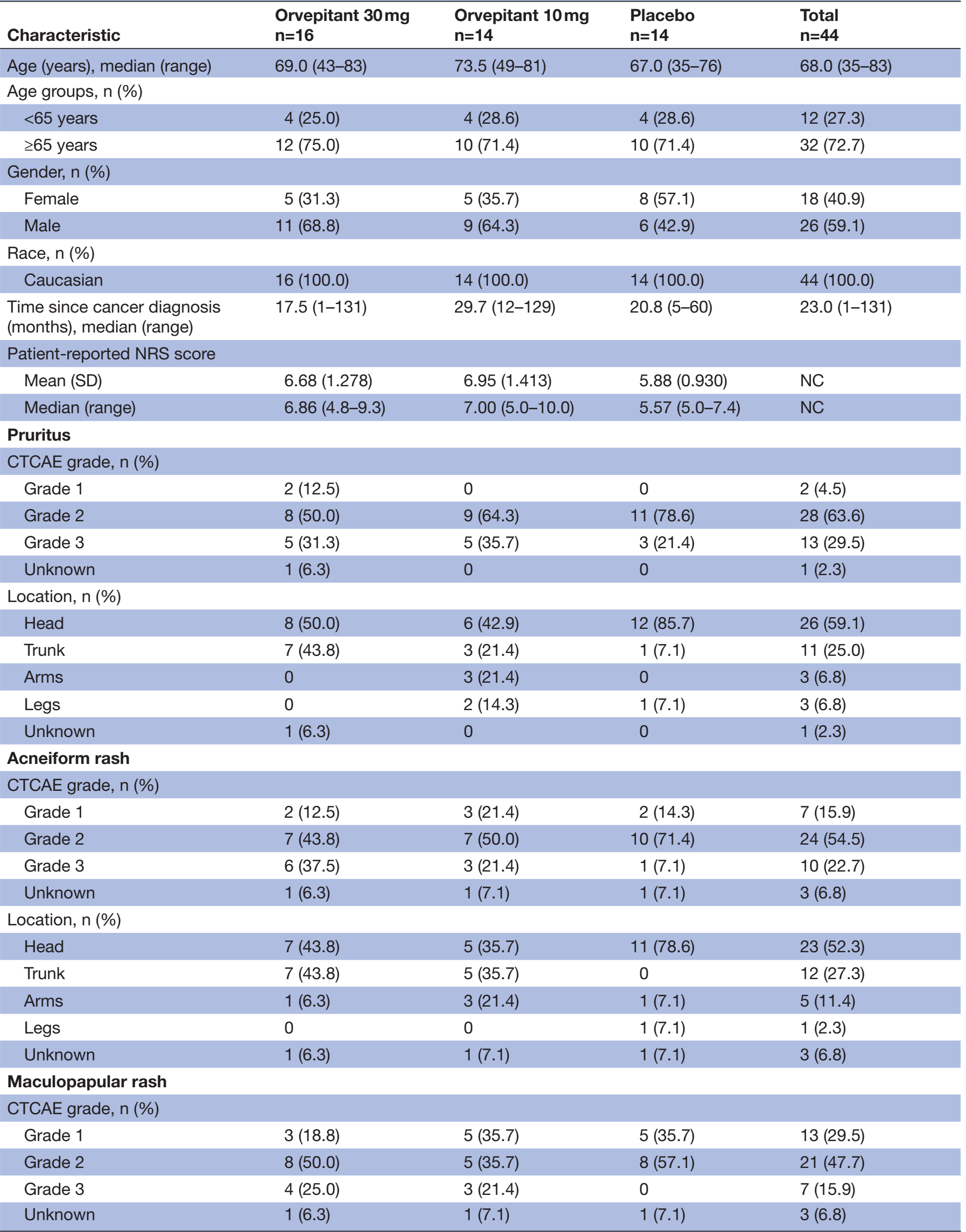

Continued 


\begin{tabular}{|c|c|c|c|c|}
\hline Characteristic & $\begin{array}{l}\text { Orvepitant } 30 \mathrm{mg} \\
\mathrm{n}=16\end{array}$ & $\begin{array}{l}\text { Orvepitant } 10 \mathrm{mg} \\
\mathrm{n}=14\end{array}$ & $\begin{array}{l}\text { Placebo } \\
\mathrm{n}=14\end{array}$ & $\begin{array}{l}\text { Total } \\
\mathrm{n}=44\end{array}$ \\
\hline \multicolumn{5}{|l|}{ Location, n (\%) } \\
\hline Head & $7(43.8)$ & $5(35.7)$ & $12(85.7)$ & $24(54.5)$ \\
\hline Trunk & $7(43.8)$ & 4 (28.6) & 0 & $11(25.0)$ \\
\hline Arms & $1(6.3)$ & $4(28.6)$ & 0 & $5(11.4)$ \\
\hline Legs & 0 & 0 & $1(7.1)$ & $1(2.3)$ \\
\hline Unknown & $1(6.3)$ & $1(7.1)$ & $1(7.1)$ & $3(6.8)$ \\
\hline
\end{tabular}

CTCAE, Common Terminology Criteria for Adverse Events; NC, not calculated; NRS, numerical rating scale.

including a planned phase III study in refractory or unexplained chronic cough following a successful phase II study in this indication. ${ }^{60}$

The efficacy results were, however, inconclusive; no significant difference between the active groups and the placebo group was observed. Patients experienced a mean reduction in itching of approximately 3 NRS points in the two orvepitant groups and the placebo group. This outcome may, of course, have resulted from the premature termination of the study and the consequent substantially reduced sample size making it difficult to determine a treatment difference. However, given there was no indication of difference between the arms, it seems unlikely even if the study had been fully recruited that a treatment effect would have been detected. This outcome stands in stark contrast to the observation studies conducted with the NK1 antagonist aprepitant. ${ }^{33-49}$ For example, in a 1-week, open-label study in 45 patients experiencing mainly EGFRI-induced severe pruritus, aprepitant therapy resulted in median visual analogue scale itch scores falling from 8 at baseline to 1 after 7 days in a refractory group resistant to standard antipruritus treatments and from 8 to 0 in a naive group ( $\mathrm{p}<0.0001$ in both groups). ${ }^{8}$ In this trial, $41(91 \%)$ patients responded to aprepitant (ie, had a $>50 \%$ reduction in pruritus intensity), and pruritus recurred in only $6(13 \%)$ patients. This difference is difficult to rationalise given that the pharmacologies of orvepitant and aprepitant are so comparable and both can achieve exposures likely to be therapeutic in humans following oral dosing. However, one plausible explanation for the results in the RELIEVE 1 study is the placebo effect that is often seen in clinical trials with subjective endpoints such as pruritus intensity. ${ }^{61}$ In this study, patients who are critically ill were receiving a modern antineoplastic therapy, and they may have had a particularly high expectation of the benefit of their EGFRI therapy in general and of orvepitant's ability to reduce pruritus and thereby improve their quality of life.

A further explanation for the RELIEVE 1 study results relates to the pathological mechanism underlying the itch in these patients. EGFRI-induced pruritus arises acutely within the first 2 weeks after initiation of the anticancer therapy ${ }^{5}$ and cutaneous accumulation, and activation of dermal mast cells ${ }^{16} 1762$ may be the most important driver of the itch signalling in these patients. This acute course contrasts with that of chronic pruritus conditions (defined as being $>6$ weeks in duration), ${ }^{63}$

Table 2 Change from baseline in patient-reported numerical reporting scale scores at week 4

\begin{tabular}{llll}
\hline Statistic & $\begin{array}{l}\text { Orvepitant } \mathbf{3 0} \mathbf{m g} \\
\mathbf{n = 1 6}\end{array}$ & $\begin{array}{l}\text { Orvepitant } \mathbf{1 0} \mathbf{m g} \\
\mathbf{n = 1 4}\end{array}$ & $\begin{array}{l}\text { Placebo } \\
\mathbf{n = 1 4}\end{array}$ \\
\hline $\mathrm{n}$ & 13 & 11 & 14 \\
\hline Mean (SD) & $-2.78(2.64)$ & $-3.04(3.06)$ & $-3.21(1.77)$ \\
\hline Median & -2.75 & -2.00 & -2.50 \\
\hline Minimum, maximum & -6.3 to 3.0 & -8.3 to 1.1 & -6.3 to 0.0 \\
$\begin{array}{l}\text { LSMEANS estimate } \\
\text { (95\% Cl) }\end{array}$ & $-2.40(-3.54$ to -1.27$)$ & $-2.53(-3.80$ to -1.27$)$ & $-3.70(-4.88$ to -2.52$)$ \\
LSMEANS SE & 0.56 & 0.62 & 0.58 \\
$\begin{array}{l}\text { Orvepitant versus placebo difference } \\
\text { (95\% Cl) }\end{array}$ & $1.30(-0.35$ to 2.95) & $1.17(-0.62$ to 2.96) & \\
\hline P value & 0.120 & 0.194 & \\
\hline
\end{tabular}

Analysis results from mixed-model repeated measures analysis (week 1 to week 4 ) of the three treatment groups analysed together in one model: change from baseline=treatment+pooled site+visit+treatment*visit+baseline results+visit*baseline covariate interaction.

LSMEANS, least-squares means. 
Table 3 Summary of secondary efficacy endpoints

Statistic

$\begin{array}{lll}\substack{\text { Orvepitant } 30 \mathrm{mg} \\ \mathrm{n}=16} & \begin{array}{l}\text { Orvepitant 10 mg } \\ \mathrm{n}=14\end{array} & \begin{array}{l}\text { Placebo } \\ \mathrm{n}=14\end{array}\end{array}$

\section{Change from baseline, (n) mean (SD)}

Patient-recorded NRS score (last three recordings) at week 1
(16) $-1.18(1.55)$

(13) $-1.66(2.48)$

(14) $-1.16(1.41)$

Patient-recorded NRS score (last three recordings) at week 2

(14) $-2.33(2.00)$

(13) -2.85 (3.43)

(13) $-2.76(1.96)$

Patient-recorded NRS score (last three recordings) at week 3

(14) $-2.16(2.56)$

(11) $-3.14(2.77)$

(14) $-3.26(2.00)$

Patient-recorded NRS score (last three recordings) at week 5

(13) $-3.19(2.88)$

(10) $-3.32(3.19)$

(14) $-3.90(2.19)$

Patient-recorded NRS score (last three recordings) at week 6

(13) $-3.24(2.89)$

(10) $-3.68(2.55)$

(13) $-4.00(1.78)$

Patient-recorded NRS score (last three recordings) at week 7

(12) $-2.49(2.91)$

(10) $-2.85(2.52)$

(12) $-4.13(2.33)$

Patient-recorded NRS score (last three recordings) at week 8

(11) $-2.86(2.91)$

(10) $-3.18(2.68)$

(12) $-4.32(2.27)$

Patient-recorded NRS score (all week) at week 1

(16) $-0.96(1.09)$

(13) $-1.34(1.93)$

(14) $-0.86(1.00)$

Patient-recorded NRS score (all week) at week 4

(13) $-2.64(2.61)$

(11) $-3.05(3.00)$

(14) -3.20 (1.96)

Patient-recorded NRS score (all week) at week 8

(11) $-2.65(2.81)$

(10) -3.15 (2.66)

(12) $-4.29(2.33)$

Clinic-visit NRS score at week 1

(14) $-1.93(1.73)$

(14) -2.21 (3.19)

(14) $-3.00(2.60)$

Clinic-visit NRS score at week 4

(13) $-3.38(2.69)$

(11) -4.27 (2.94)

(14) $-4.14(2.18)$

Clinic-visit NRS score at week 8

(13) $-3.50(2.71)$

(11) -3.91 (2.66)

(12) $-3.92(2.35)$

Patient-recorded NRS score at day 2

(16) $-0.61(1.29)$

(12) $-0.84(1.24)$

(13) $-0.33(0.74)$

Patient-recorded NRS score at day 3

(14) $-0.96(0.99)$

(11) -0.86 (1.64)

(13) $-0.41(0.65)$

Patient-recorded NRS score at day 4

(14) -0.85 (1.09)

(12) $-1.04(1.88)$

(14) $-0.81(1.28)$

Patient-recorded NRS score at day 5

(13) $-1.35(1.12)$

(12) $-1.29(2.23)$

(13) $-1.18(1.45)$

Patient-recorded NRS score at day 6

(14) $-1.28(1.68)$

(11) $-1.31(2.20)$

(11) $-1.30(1.54)$

Patient-recorded NRS score at day 7

(14) $-1.42(2.30)$

(12) -1.87 (3.63)

(13) $-1.33(1.89)$

Patient-recorded NRS score at day 8

(14) -1.85 (2.31)

(11) $-1.83(2.42)$

(14) $-1.88(2.03)$

Skindex-16 at week 1: symptoms

(14) $-12.56(22.25)$

(13) 1.24 (25.05)

(13) $-2.88(18.50)$

Skindex-16 at week 4: symptoms

(13) -8.29 (25.06)

(11) $-9.09(36.94)$

(13) -7.69 (29.56)

Skindex-16 at week 8: symptoms

(12) -8.09 (23.60)

(11) $-8.71(36.19)$

(12) $-4.02(33.30)$

Skindex-16 at week 1: emotions

(14) -44.73 (16.35)

(13) $-21.52(27.80)$

(13) $-21.29(18.20)$

Skindex-16 at week 4: emotions

(13) $-32.60(24.96)$

(11) -31.96 (36.34)

(13) $-25.69(26.54)$

Skindex-16 at week 8: emotions

(12) -35.37 (30.88)

(11) -37.23 (28.13)

(12) $-36.86(26.32)$

Skindex-16 at week 1: functioning

(14) -13.33 (16.69)

(13) -12.05 (29.08)

(13) $-1.28(13.51)$

Skindex-16 at week 4: functioning

(13) 2.05 (26.51)

(11) -11.51 (36.07)

(13) $-1.80(20.40)$

Skindex-16 at week 8: functioning

(12) $-0.83(28.04)$

(11) -22.73 (25.64)

(12) $-5.00(16.17)$

LSEQ at week 1: getting to sleep

(13) $-12.08(22.10)$

(12) $-9.82(23.50)$

(12) $-6.45(16.97)$

LSEQ at week 4: getting to sleep

(12) -12.36 (19.61)

(9) 3.37 (23.64)

(12) -8.47 (18.19)

LSEQ at week 8: getting to sleep

(11) -4.57 (13.67)

(9) 2.04 (25.47)

(11) -7.06 (23.68)

LSEQ at week 1: quality of sleep

(13) -6.77 (26.98)

(12) -13.29 (33.39)

(12) -5.67 (15.39)

LSEQ at week 4: quality of sleep

(12) $-6.46(20.63)$

(9) -8.61 (39.09)

(12) $-9.13(17.60)$

LSEQ at week 8: quality of sleep

(11) $-6.73(21.81)$

(9) -17.22 (34.00)

(11) -10.14 (26.73)

LSEQ at week 1: awake following sleep

(13) 5.85 (19.80)

(12) -12.08 (32.39)

(12) $-2.04(15.50)$

LSEQ at week 4: awake following sleep

(12) 8.29 (16.22)

(8) $-8.00(43.83)$

(12) -4.13 (19.93)

LSEQ at week 8: awake following sleep

(11) 7.23 (16.91)

(9) $-10.72(36.14)$

(11) -7.55 (30.06)

LSEQ at week 1: behaviour following wakening

(13) 3.90 (12.44)

(12) -3.89 (32.06)

(12) -3.67 (7.67)

LSEQ at week 4: behaviour following wakening

(12) 1.03 (15.97)

(9) $5.78(46.41)$

(12) $-9.89(14.53)$

LSEQ at week 8: behaviour following wakening

(11) -0.36 (13.73)

(9) 6.82 (49.17)

(11) $-1.82(19.95)$

Change from baseline, $\mathrm{n}(\%)$

VRS score at week 1 
Table 3 Continued

\begin{tabular}{|c|c|c|c|}
\hline Statistic & $\begin{array}{l}\text { Orvepitant } 30 \mathrm{mg} \\
\mathrm{n}=16\end{array}$ & $\begin{array}{l}\text { Orvepitant } 10 \mathrm{mg} \\
\mathrm{n}=14\end{array}$ & $\begin{array}{l}\text { Placebo } \\
n=14\end{array}$ \\
\hline Improved & $8(57.1)$ & $9(64.3)$ & $9(64.3)$ \\
\hline No change & $5(35.7)$ & $3(21.4)$ & $4(28.6)$ \\
\hline Worsened & $1(7.1)$ & $2(14.3)$ & $1(7.1)$ \\
\hline \multicolumn{4}{|l|}{ VRS score at week 4} \\
\hline Improved & $10(76.9)$ & $8(80.0)$ & $11(78.6)$ \\
\hline No change & $3(23.1)$ & $2(20.0)$ & $2(14.3)$ \\
\hline Worsened & 0 & 0 & $1(7.1)$ \\
\hline \multicolumn{4}{|l|}{ VRS score at week 8} \\
\hline Improved & $9(75.0)$ & $9(81.8)$ & $9(81.8)$ \\
\hline No change & $3(25.0)$ & $2(18.2)$ & $2(18.2)$ \\
\hline Worsened & 0 & 0 & 0 \\
\hline \multicolumn{4}{|l|}{ Change from week 4 , (n) mean (SD) } \\
\hline Patient-recorded NRS score (last three recordings) at week 5 & (13) $-0.41(1.409)$ & (10) $-0.47(1.989)$ & (14) $-0.69(0.991)$ \\
\hline Patient-recorded NRS score (last three recordings) at week 6 & (13) $-0.46(1.561)$ & $(10)-0.83(2.196)$ & (13) $-0.69(0.897)$ \\
\hline Patient-recorded NRS score (last three recordings) at week 7 & (12) $0.17(1.972)$ & (10) $0.00(3.604)$ & (12) $-0.72(1.127)$ \\
\hline Patient-recorded NRS score (last three recordings) at week 8 & $(11)-0.42(2.071)$ & $(10)-0.33(3.728)$ & (12) $-0.92(1.084)$ \\
\hline VRS score at week 8 & $(12)-0.08(1.730)$ & (11) 0.36 (3.501) & (12) 0.08 (1.165) \\
\hline \multicolumn{4}{|l|}{ Patients, n (\%) } \\
\hline Prescribed rescue medication & $6(37.5)$ & $4(28.6)$ & $2(14.3)$ \\
\hline Used rescue medication & $3(18.8)$ & $2(14.3)$ & $2(14.3)$ \\
\hline EGFRI dose reduction & $3(18.8)$ & $2(14.3)$ & $2(14.3)$ \\
\hline Withdrawal because of intense uncontrolled pruritus & 0 & 0 & 0 \\
\hline
\end{tabular}

EGFRI, epidermal growth factor receptor inhibitor; LSEQ, Leeds Sleep Evaluation Questionnaire; NRS, numerical rating scale; VRS, verbal rating scale.

which are now linked to the sensitisation of itch signalling pathways similar to chronic pain, such that patients may report spontaneous itch (alloknesis) or an enhanced itch to normal itch-evoking stimuli (hyperknesis). ${ }^{32} 6465$ NK1 antagonists have shown great promise in randomised, placebo-controlled clinical studies as treatments for chronic pruritus conditions in general ${ }^{66} 67$ as well as

Table 4 Drug-related adverse events

\begin{tabular}{|llll}
\hline & $\begin{array}{l}\text { Orvepitant } \\
\mathbf{3 0} \mathbf{m g} \\
\mathbf{n = 1 6} \\
\mathbf{n ~ ( \% )}\end{array}$ & $\begin{array}{l}\text { Orvepitant } \\
\mathbf{1 0} \mathbf{m g} \\
\mathbf{n = 1 4} \\
\mathbf{n ~ ( \% )}\end{array}$ & $\begin{array}{l}\text { Placebo } \\
\mathbf{n = 1 4} \\
\mathbf{n}(\%)\end{array}$ \\
\hline $\begin{array}{llll}\text { Any drug-related AE } \\
\text { Mild AEs }\end{array}$ & $3(18.8)$ & $1(7.1)$ & 0 \\
\hline $\begin{array}{l}\text { Asthenia } \\
\text { Dizziness }\end{array}$ & $1(6.3)$ & 0 & 0 \\
\hline $\begin{array}{c}\text { Dry mouth } \\
\text { Moderate AEs }\end{array}$ & 0 & $1(7.1)$ & 0 \\
\hline Hyperhidrosis & $1(6.3)$ & 0 & 0 \\
\hline
\end{tabular}

$\mathrm{AE}$, adverse event. specifically for prurigo nodularis, ${ }^{68}$ atopic dermatitisassociated pruritus ${ }^{69}$ and psoriasis-associated pruritus. ${ }^{70}$ Orvepitant has shown efficacy against chronic refractory cough, which has also been recognised as a neural hypersensitivity syndrome. ${ }^{60}$ Thus, NK1 antagonists may lack efficacy in acute pruritic conditions driven by cutaneous mast cells, such as EGFRI-induced pruritus, while being effective in chronic pruritus conditions by addressing itch pathway sensitisation.

A final explanation is that the improvement in itch scores seen in the two orvepitant groups and the placebo group may be attributable to the natural course of pruritus over the weeks following the initiation of EGFRI treatment. It is now known that patterns of cutaneous toxicities with EGFRI treatment can vary with time; for example, the intensity of acneiform rash that is associated with pruritus rises and falls dramatically in the first month. ${ }^{71}$ If this were the case for itch intensity, it would be difficult to show a benefit against such a dynamic and self-limiting background.

\section{Strengths and limitations of the study}

The RELIEVE 1 study was the first randomised, doubleblind, placebo-controlled study of an NK1 receptor 
antagonist for EGFRI-induced pruritus. The enrolment target was not reached because of recruitment problems in the critically ill target population. A similar response was seen in both placebo and active groups, a result for which there are several possible explanations. Nonetheless, this randomised, controlled study provided insights into the course, itch characteristics and possible mechanisms of EGFRI-induced pruritus that may inform future studies.

\section{Implications for future studies}

Recruitment for this study was stopped after 20 months when only 44 of the planned 90 patients had been enrolled. Despite evidence in the literature of a high prevalence of EGFRI-induced pruritus, ${ }^{1-11} 13507273$ we experienced substantial difficulty identifying patients with severe enough pruritus (ie, NRS score $\geq 5$ ) to enable detection of post-treatment change. Study enrolment may have been limited by the fact that all investigators were oncologists, who are faced with multiple AEs in patients receiving EGFRIs (eg, diarrhoea, rash, asthenia, nausea and vomiting, conjunctivitis, mucositis) that may have taken precedence over pruritus, a purely subjective symptom that is not widely reported in the oncology community. ${ }^{10}$ Patients may also have been unwilling to enter the study because pruritus is not a major priority for them compared with their cancer.

NK1 antagonists may still hold potential for treatment of skin toxicities experienced by patients with cancer treated with EGFRIs or other targeted therapies. However, future studies will require a more complete understanding of the epidemiology and course of target cancer therapy-induced pruritus to enable appropriate selection and sizing of the patient population to achieve statistical power and a design that minimises or quantifies the placebo effect. Furthermore, greater knowledge of the pathological mechanism underlying the pruritus in this condition is needed. Without these advances, the experience of this trial shows that further investigation of this particular drug-induced pruritus condition at the current juncture will prove challenging.

\section{Author affiliations}

${ }^{1}$ Medical Oncology, Universita Campus Bio-Medico di Roma Facolta di Medicina e Chirurgia, Roma, Italy

${ }^{2}$ NeRRe Therapeutics, Stevenage, UK

${ }^{3}$ Adnovate Clinical Development Strategies, East Sussex, UK

${ }^{4}$ Oncology Unit, ASO SS Antonio e Biagio e C Arrigo, Alessandria, Italy

${ }^{5}$ Biometrics Division, Cromsource, Stirling, UK

${ }^{6}$ Department of Dermatology, Memorial Sloan Kettering Cancer Center, New York, New York, USA

${ }^{7}$ Idfac, Devon, UK

${ }^{8}$ Center for Chronic Pruritus, University Hospital Münster, Münster, Germany

Acknowledgements We thank Anne McDonough, a professional medical writer who provided medical writing support funded by NeRRe Therapeutics.

Contributors Study concept and design: BV, MT, PH, MEL, ER, GT, AW, SS. Data acquisition: BV, PG. Quality control of data and algorithms: PH, DJ. Data analysis and interpretation: BV, MT, AD, SS. Statistical analysis: DJ. Manuscript preparation: MT. Manuscript editing: BV, MT, SS. All authors read, edited and approved the final manuscript.
Funding This work was supported and sponsored by NeRRe Therapeutics. MEL is funded in part through NIH/NCl Cancer Center Support Grant P30 CA008748.

Disclaimer The sponsor was involved in the study design; in the collection, analysis and interpretation of the data; in the writing of the report; and in the decision to submit the paper for publication.

Competing interests MT is a current employee and ER is a past employee of NeRRe Therapeutics, and both are inventors on a granted patent on novel uses of orvepitant. BV and PG received payment from NeRRe as investigators in this study. AD received payment from NeRRe for service as the chief medical officer for this study. DJ is an employee of Cromsource, who received payment from NeRRe for statistical analysis of this study. PH has received payment from NeRRe as a consultant. MEL reports receiving personal fees from Legacy Healthcare Services, AdgeroBio Pharmaceuticals, Amryt Pharma, Celldex Therapeutics, Debiopharm, Galderma Research and Development, Johnson \& Johnson, Novocure, Lindi Skin, Merck Sharp and Dohme, Helsinn Healthcare, Janssen Research \& Development, Menlo Therapeutics, Novartis Pharmaceuticals, F Hoffmann-La Roche, AbbVie, Boehringer Ingelheim Pharma, Allergan, Amgen, ER Squibb \& Sons, EMD Serono, AstraZeneca Pharmaceuticals, Genentech, Leo Pharma, Seattle Genetics, Bayer, Männer SAS, Lutris Pharma, Pierre Fabre, Paxman Cooler, Adjucare, Dignitana, Biotechspert, Teva Pharmaceuticals Mexico, Parexel, OnQuality Pharmaceuticals, Novartis, Our Brain Bank, Millennium Pharmaceuticals, and research funding from Berg Health, Bristol-Myers Squibb, Lutris Pharma, Novocure, Paxman, Biotest and Veloce BioPharma. GT reports no conflicts of interest. AW reports receiving payment from NeRRe as chair of the advisory board and from Advent Life Sciences for consultancy, Canbex Therapeutics as a non-executive director (past position), Calcico Therapeutics as chairman (past position) and a non-executive director (past position), and the Wellcome Trust as a member of grant committees. SS reports receiving payment from NeRRe as a member of the advisory board and from Almirall, Astellas Pharma, Beiersdorf, Celgene, Chugai Pharma, Creabilis, Daiichi Sankyo, Galderma, Helsinn, Kiniska Pharmaceuticals, Kneipp, Maruho, Merz Pharma, Novartis, Pierre Fabre Laboratories, Sienna Biopharmaceuticals and Ziarco as a member of their advisory boards and from Menlo Therapeutics as an investigator and participation as an investigator in trials sponsored by Dermascence, Trevi Therapeutics and Vanda Pharmaceuticals.

Patient consent for publication Not required.

Ethics approval This trial was approved by the NRES Committee North East-Tyne \& Wear South for the UK investigational sites and Comitato etico dell'Università Campus Bio-Medico di Roma for those in Italy.

Provenance and peer review Not commissioned; externally peer reviewed.

Data availability statement Data are available upon reasonable request. The deidentified data set for this study is available upon reasonable request from the study sponsor NeRRe Therapeutics.

Open access This is an open access article distributed in accordance with the Creative Commons Attribution Non Commercial (CC BY-NC 4.0) license, which permits others to distribute, remix, adapt, build upon this work non-commercially, and license their derivative works on different terms, provided the original work is properly cited, appropriate credit is given, any changes made indicated, and the use is non-commercial. See: http://creativecommons.org/licenses/by-nc/4.0/.

\section{ORCID iDs}

Bruno Vincenzi http://orcid.org/0000-0001-8222-9025

Mike Trower http://orcid.org/0000-0003-0412-5719

Ajay Duggal http://orcid.org/0000-0003-3294-616X

Pamela Guglielmini http://orcid.org/0000-0003-3612-7786

Peter Harris http://orcid.org/0000-0002-8374-3859

David Jackson http://orcid.org/0000-0002-4448-8648

Mario E Lacouture http://orcid.org/0000-0002-4818-3710

Emiliangelo Ratti http://orcid.org/0000-0002-7352-4695

Giuseppe Tonini http://orcid.org/0000-0003-4442-8677

Andrew Wood http://orcid.org/0000-0001-7536-6398

Sonja Ständer http://orcid.org/0000-0003-3612-7786

\section{REFERENCES}

1 Boone SL, Rademaker A, Liu D, et al. Impact and management of skin toxicity associated with anti-epidermal growth factor receptor therapy: survey results. Oncology 2007;72:152-9.

2 Balagula Y, Lacouture ME, Cotliar JA. Dermatologic toxicities of targeted anticancer therapies. J Support Oncol 2010;8:149-61. 
3 Fischer A, Rosen AC, Ensslin CJ, et al. Pruritus to anticancer agents targeting the EGFR, BRAF, and CTLA-4. Dermatol Ther 2013;26:135-48.

4 Lacouture ME, Anadkat MJ, Bensadoun R-J, et al. Clinical practice guidelines for the prevention and treatment of EGFR inhibitor-associated dermatologic toxicities. Support Care Cancer 2011;19:1079-95.

5 Clabbers JMK, Boers-Doets CB, Gelderblom H, et al. Xerosis and pruritus as major EGFRI-associated adverse events. Support Care Cancer 2016;24:513-21.

6 Joshi SS, Ortiz S, Witherspoon JN, et al. Effects of epidermal growth factor receptor inhibitor-induced dermatologic toxicities on quality of life. Cancer 2010;116:3916-23.

7 Rosen AC, Case EC, Dusza SW, et al. Impact of dermatologic adverse events on quality of life in 283 cancer patients: a questionnaire study in a dermatology referral clinic. Am J Clin Dermatol 2013;14:327-33.

8 Santini D, Vincenzi B, Guida FM, et al. Aprepitant for management of severe pruritus related to biological cancer treatments: a pilot study. Lancet Oncol 2012;13:1020-4.

9 AstraZeneca Pharmaceuticals LP. Tagrisso [prescribing information]. Wilmington, DE: AstraZeneca Pharmaceuticals LP, 2015.

10 Bauer KA, Hammerman S, Rapoport B, et al. Completeness in the reporting of dermatologic adverse drug reactions associated with monoclonal antibody epidermal growth factor receptor inhibitors in phase II and III colorectal cancer clinical trials. Clin Colorectal Cancer 2008;7:309-14.

11 Gandhi M, Oishi K, Zubal B, et al. Unanticipated toxicities from anticancer therapies: survivors' perspectives. Support Care Cancer 2010;18:1461-8.

12 Cho S, Lee J, Lim J, et al. Pruritus in patients under targeted anticancer therapy: a multidimensional analysis using the 5-D itch scale. Acta Derm Venereol 2019;99:435-41.

13 Chan A, Tan EH. How well does the MESTT correlate with CTCAE scale for the grading of dermatological toxicities associated with oral tyrosine kinase inhibitors? Support Care Cancer 2011;19:1667-74.

14 Steinhoff MS, von Mentzer B, Geppetti P, et al. Tachykinins and their receptors: contributions to physiological control and the mechanisms of disease. Physiol Rev 2014;94:265-301.

15 Benecke H, Lotts T, Ständer S. Investigational drugs for pruritus. Expert Opin Investig Drugs 2013;22:1167-79.

16 Gerber PA, Buhren BA, Cevikbas F, et al. Preliminary evidence for a role of mast cells in epidermal growth factor receptor inhibitorinduced pruritus. J Am Acad Dermatol 2010;63:163-5.

17 Gerber PA, Buhren BA, Homey B. More on aprepitant for erlotinibinduced pruritus. N Engl J Med 2011;364:486-7.

18 Harrison S, Geppetti P, Substance P. Substance P. Int J Biochem Cell Biol 2001;33:555-76.

19 Azimi E, Reddy VB, Pereira PJS, et al. Substance P activates Masrelated $\mathrm{G}$ protein-coupled receptors to induce itch. J Allergy Clin Immunol 2017;140:447-53.

20 Carstens E, Akiyama T. Central mechanisms of itch. Curr Probl Dermatol 2016;50:11-17.

21 Carstens EE, Carstens MI, Simons CT, et al. Dorsal horn neurons expressing NK-1 receptors mediate scratching in rats. Neuroreport 2010;21:303-8.

22 Akiyama T, Nguyen T, Curtis E, et al. A central role for spinal dorsal horn neurons that express neurokinin-1 receptors in chronic itch. Pain 2015;156:1240-6.

23 Gao Z-R, Chen W-Z, Liu M-Z, et al. Tac1-Expressing neurons in the periaqueductal gray facilitate the Itch-Scratching cycle via descending regulation. Neuron 2019;101:45-59.

24 Hägermark O, Hökfelt T, Pernow B. Flare and itch induced by substance P in human skin. J Invest Dermatol 1978;71:233-5.

25 Heyer G, Hornstein OP, Handwerker HO. Reactions to intradermally injected substance $P$ and topically applied mustard oil in atopic dermatitis patients. Acta Derm Venereol 1991;71:291-5.

26 Thomsen JS, Sonne M, Benfeldt E, et al. Experimental itch in sodium lauryl sulphate-inflamed and normal skin in humans: a randomized, double-blind, placebo-controlled study of histamine and other inducers of itch. Br J Dermatol 2002;146:792-800.

27 Andoh T, Nagasawa T, Satoh M, et al. Substance P induction of itch-associated response mediated by cutaneous NK1 tachykinin receptors in mice. J Pharmacol Exp Ther 1998;286:1140-5.

28 Trower MK, Fisher A, Upton N, et al. Neurokinin-1 receptor antagonist orvepitant is an effective inhibitor of itch-associated response in a Mongolian gerbil model of scratching behaviour. Exp Dermatol 2014;23:858-60

29 Costantini VJA, Corsi M, Dünstl G, et al. The NK1 receptor antagonist aprepitant attenuates NK1 agonist-induced scratching behaviour in the gerbil after intra-dermal, topical or oral administration. Exp Dermatol 2015;24:312-4.

30 Ueda Y, Inoue T, Rahman MA, et al. A new chronic itch mode accompanied by skin lesions in hairless mice. Int Immunopharmacol 2006;6:1609-15.

31 Ständer S, Luger TA. Nk-1 antagonists and itch. Handb Exp Pharmacol 2015;226:237-55.

32 Ständer S, Yosipovitch G. Substance P and neurokinin 1 receptor are new targets for the treatment of chronic pruritus. Br J Dermatol 2019

33 Ständer S, Siepmann D, Herrgott I, et al. Targeting the neurokinin receptor 1 with aprepitant: a novel antipruritic strategy. PLoS One 2010;5:e10968.

34 Duval A, Dubertret L. Aprepitant as an antipruritic agent? N Engl J Med 2009;361:1415-6.

35 Booken N, Heck M, Nicolay JP, et al. Oral aprepitant in the therapy of refractory pruritus in erythrodermic cutaneous T-cell lymphoma. $\mathrm{Br} \mathrm{J}$ Dermatol 2011;164:665-7.

36 Torres T, Fernandes I, Selores M, et al. Aprepitant: evidence of its effectiveness in patients with refractory pruritus continues. J Am Acad Dermatol 2012;66:e14-15

37 Ladizinski B, Bazakas A, Olsen EA. Aprepitant: a novel neurokinin-1 receptor/substance $\mathrm{P}$ antagonist as antipruritic therapy in cutaneous T-cell lymphoma. J Am Acad Dermatol 2012;67:e198-9.

38 Vincenzi B, Fratto ME, Santini D, et al. Aprepitant against pruritus in patients with solid tumours. Support Care Cancer 2010:18:1229-30.

39 Vincenzi B, Tonini G, Santini D. Aprepitant for erlotinib-induced pruritus. N Engl J Med 2010;363:397-8

40 Levêque D. Aprepitant for erlotinib-induced pruritus. N Engl J Med 2010;363:1680-1.

41 Mir O, Blanchet B, Goldwasser F. More on aprepitant for erlotinibinduced pruritus. N Engl J Med 2011;364:487.

42 Vincenzi B, Tonini G, Santini D. Aprepitant for erlotinib-induced pruritus. N Engl J Med 2010;364:397-8.

43 Ally MS, Gamba CS, Peng DH, et al. The use of aprepitant in brachioradial pruritus. JAMA Dermatol 2013;149:627-8.

44 Huh JW, Jeong Y-I, Choi K-H, et al. Treatment for refractory pruritus using oral aprepitant. Ann Dermatol 2016;28:124-5.

45 Jiménez Gallo D, Albarrán Planelles C, Linares Barrios M, et al. Treatment of pruritus in early-stage hypopigmented mycosis fungoides with aprepitant. Dermatol Ther 2014;27:178-82.

46 Borja-Consigliere HA, López-Pestaña A, Vidal-Manceñido MJ et al. Aprepitant in the treatment of refractory pruritus secondary to cutaneous T-cell lymphoma. Actas Dermosifiliogr 2014;105:716-8.

47 Song JS, Tawa M, Chau NG, et al. Aprepitant for refractory cutaneous T-cell lymphoma-associated pruritus: 4 cases and a review of the literature. BMC Cancer 2017;17:200.

48 Qin H, Wang F, Wang K, et al. Aprepitant for gefitinib-induced refractory pruritus in Chinese malignancy population. Ann. Transl. Med 2019;7:54.

49 Seki N, Ochiai R, Haruyama T, et al. Need for flexible adjustment of the treatment schedule for aprepitant administration against erlotinib-induced refractory pruritus and skin rush. Case Rep Oncol 2019;12:84-90

50 Santoni M, Conti A, Andrikou K, et al. Risk of pruritus in cancer patients treated with biological therapies: a systematic review and meta-analysis of clinical trials. Crit Rev Oncol Hematol 2015:96:206-19.

51 Di Fabio R, Alvaro G, Braggio S, et al. Identification, biologica characterization and pharmacophoric analysis of a new potent and selective NK1 receptor antagonist clinical candidate. Bioorg Med Chem 2013;21:6264-73.

52 Lindström E, von Mentzer B, Påhlman I, et al. Neurokinin 1 recepto antagonists: correlation between in vitro receptor interaction and in vivo efficacy. J Pharmacol Exp Ther 2007;322:1286-93.

53 Duffy RA, Varty GB, Morgan CA, et al. Correlation of neurokinin (NK) 1 receptor occupancy in gerbil striatum with behavioral effects of NK1 antagonists. J Pharmacol Exp Ther 2002;301:536-42.

54 Kramer MS, Cutler N, Feighner J, et al. Distinct mechanism for antidepressant activity by blockade of central substance $P$ receptors. Science 1998;281:1640-5.

55 Ratti E, Bettica P, Alexander R, et al. Full central neurokinin-1 receptor blockade is required for efficacy in depression: evidence from orvepitant clinical studies. J Psychopharmacol 2013;27:424-34.

56 Bergström M, Hargreaves RJ, Burns HD, et al. Human positron emission tomography studies of brain neurokinin 1 receptor occupancy by aprepitant. Biol Psychiatry 2004;55:1007-12.

57 Phan N, Blome C, Fritz F, et al. Assessment of pruritus intensity: prospective study on validity and reliability of the visual analogue scale, numerical rating scale and verbal rating scale in 471 patients with chronic pruritus. Acta Derm Venereol 2012;92:502-7. 
58 Chren M-M. The Skindex instruments to measure the effects of skin disease on quality of life. Dermatol Clin 2012;30:231-6.

59 Pinto C, Barone CA, Girolomoni G, et al. Management of skin toxicity associated with cetuximab treatment in combination with chemotherapy or radiotherapy. Oncologist 2011;16:228-38.

60 Smith J, Allman D, Badri H, et al. The neurokinin-1 receptor antagonist Orvepitant is a novel antitussive therapy for chronic refractory cough: results from a phase 2 pilot study (VOLCANO-1). Chest 2020;157:111-8.

61 van Laarhoven AIM, van der Sman-Mauriks IM, Donders ART, et al. Placebo effects on itch: a meta-analysis of clinical trials of patients with dermatological conditions. J Invest Dermatol 2015;135:1234-43.

62 Mascia F, Lam G, Keith C, et al. Genetic ablation of epidermal EGFR reveals the dynamic origin of adverse effects of anti-EGFR therapy. Sci Transl Med 2013;5:199ra110.

63 Ständer S, Weisshaar E, Mettang T, et al. Clinical classification of itch: a position paper of the International forum for the study of itch. Acta Derm Venereol 2007:87:291-4.

64 Andersen HH, Akiyama T, Nattkemper LA, et al. Alloknesis and hyperknesis-mechanisms, assessment methodology, and clinical implications of itch sensitization. Pain 2018;159:1185-97.

65 Ikoma A, Fartasch M, Heyer G, et al. Painful stimuli evoke itch in patients with chronic pruritus: central sensitization for itch. Neurology 2004;62:212-7.

66 Ständer S, Spellman MC, Kwon P, et al. The NK1 receptor antagonist serlopitant for treatment of chronic pruritus. Expert Opin Investig Drugs 2019;28:659-66.
67 Yosipovitch G, Ständer S, Kerby MB, et al. Serlopitant for the treatment of chronic pruritus: results of a randomized, multicenter, placebo-controlled phase 2 clinical trial. J Am Acad Dermatol 2018;78:882-91.

68 Ständer S, Kwon P, Hirman J, et al. Serlopitant reduced pruritus in patients with Prurigo nodularis in a phase 2, randomized, placebocontrolled trial. J Am Acad Dermatol 2019;80:1395-402.

69 Vanda Pharmaceuticals Inc. Vanda's tradipitant improves itch and disease severity in patients with atopic dermatitis, 2017. Available: https://vandapharmaceuticalsinc.gcs-web.com/node/8091/pdf [Accessed 28 Aug 2019].

70 U.S. National Library of Medicine. study of the efficacy, safety and tolerability of serlopitant for the treatment of pruritus (itch) with plaque psoriasis, 2019. Available: https://clinicaltrials.gov/ct2/show/ results/NCT03343639?term=MTI-109\&rank=1 [Accessed 28 Aug 2019].

71 Beech J, Germetaki T, Judge M, et al. Management and grading of EGFR inhibitor-induced cutaneous toxicity. Future Oncol 2018;14:2531-41.

72 Ensslin CJ, Rosen AC, Wu S, et al. Pruritus in patients treated with targeted cancer therapies: systematic review and meta-analysis. $J$ Am Acad Dermatol 2013;69:708-20.

73 Lacouture ME, Schadendorf D, Chu C-Y, et al. Dermatologic adverse events associated with afatinib: an oral ErbB family blocker. Expert Rev Anticancer Ther 2013;13:721-8. 